\title{
Cell-free Conversion of Castasterone in Cultured Cells of Phaseolus vulgaris and Marchantia polymorpha
}

\author{
Tae-Wuk Kim, Hyun-Hee Park, and Seong-Ki Kim* \\ Deparment of Life Science, Chung-Ang Cniversitw. Seoul 156-756, Korea \\ Received Mav 18, 2004
}

Key Words : Brassinosteroids. Castasterone. Metabolism. Phaseolus vulgaris. Marchantia polvmorpha

Brassinosteroids (BRs) are steroidal plant hormones. which are required for the normal growth and development of plants. Castasterone (CS) and brassinolide (BL) are the most frequently identified BRs in the plant kingdon., ${ }^{1,2}$ Feeding experiments using isotope-labeled substrates revealed that $\mathrm{BL}$ is biosynthesized from $\mathrm{CS}$ by 7-0xalactonation. 3,4 However. many plants which possess a fair amount of CS contain very low levels of BL. ${ }^{1.2}$ In addition, in plants which can convert CS to BL. the conversion rate is extremely low. yielding high levels of $\mathrm{CS}$ in the plants. ${ }^{1,5}$ Because $\mathrm{CS}$. as well as BL, is known to induce feedback regulation of earlier steps in BR biosynthesis pathways. ${ }^{6}$ accumulation of $\mathrm{CS}$ may limit or alter BR biosynthesis in plants. Therefore. endogenous levels of CS should be reduced. after BL production. to a level below that at which feedback regulation can occur. This is a difficult proposition, as little is yet known about the catabolisn of CS. This dearth of available data prompted us to investigate the catabolism of CS in cultured Phaseohts vilgaris and Marchantia polymorpha cells. in which the presence of CS and BL and conversion of $\mathrm{CS}$ to $\mathrm{BL}$ have been demonstrated. $1.2,7$

Cultured cells $(5 \mathrm{~g})$ of $P$. nigaris and $M$ polvmorpha were homogenized ${ }^{7}$ and centrifiged at $8.000 \times \mathrm{g}$ for 10 minutes. and the resulting supernatants were re-centrifuged at $20,000 \times \mathrm{g}$ for $30 \mathrm{~min}$. Cold acetone was then added to the obtained supernatants (funal volume $40 \%$ ), and the acetone precipitates were re-suspended in $0.1 \mathrm{M} \mathrm{Na}$ phosphate buffer (pH 7.4) containing $1.5 \mathrm{mM} \mathrm{2-mercaptoethanol} \mathrm{and} 30 \%$ glycerol for crude enzyme solutions.

Non-labeled CS and NADPH ( $4.8 \mathrm{mM}$ ) were added to the enzyme solutions as a substrate and a cofactor. respectively. to examine catabolism of $\mathrm{CS}$ in the plants. After incubating at $37^{\circ} \mathrm{C}$ for 30 minutes. the assay mixtures were extracted with ethyl acetate $(1.2 \mathrm{~mL} \times 3)$. The obtained ethyl acetate soluble fractions were loaded on a Sep-Pak $\mathrm{C}_{18}$ cartridge eluted with $50 \%$. and $100 \%$ methanol ( $5 \mathrm{~mL}$ each). The $100 \%$ methanol fractions were further purified by reversed phase HPLC (Nova Pak, C $18.8 \times 100 \mathrm{~mm}$ ) and eluted with $40 \%$ acetonitrile at a flow rate of $1 \mathrm{~mL} \mathrm{~min}^{-1}$. Fractions were collected every min, and analyzed by a preparative TLC (Merck. HPTLC $F_{254}$ ) developed with a $6: 1$ mixture of chloroform and methanol. Besides fraction 19-21. which contained CS (added as the substrate), fraction 13-15 exlibited a BR-like blue-purplish spot at $R_{f} 0.30$. The metabolite in the fractions was analyzed by GC-MS/-SIM after methaneboronation.

In GC-MS. bismethaneboronate (BMB) of the metabolite showed a molecular ion at $m z 498$ and the most abundant ion at $m z 141$, due to the fission of $\mathrm{C} 20 / \mathrm{C} 22$, which was reduced in mass compared with $C S B M B$. The mass reduction suggests that a methyl in CS was eliminated in the metabolite. Therefore, the metabolite was proposed to be either 26-norCS or 28-norCS. In GC-MS, BMB of 26-norCS and 28-norCS showed basically the same mass spectrum. but their retention times on GC were clearly different. As shown in Table $1, G C$ retention time of BMB of the metabolite was equal to that of 26 -norCS BMB. Consequently. the metabolite was characterized as 26-norCS. 26-NorCS showed approximately one-tenth the level of activity of CS, indicating that 26-norCS is a catabolite of CS in plant cells. Because isotope-labeled $26-n$ orCS is not available, activity for the enzyme cataly zing the conversion of CS to 26-norCS, namely CS C-26 demethylase. was measured by GC-SIM based quantification method. yielding 0.90 and $0.31 \mathrm{ng} \mathrm{mg}^{-1}$

Table 2. Activity of CS 6-oxidase and CS C-26 demethylase in cultured cells of $P$. vulgaris and $\mathrm{H}$. polymorpha

\begin{tabular}{lcc}
\hline \multirow{2}{*}{ Enzyme } & \multicolumn{2}{c}{ Activity $^{a}$} \\
\cline { 2 - 3 } & P. wllgaris & H. potymorpha \\
\hline CS6-0xidase & 0.09 & 0.03 \\
CSC-26 demethylase & 0.90 & 0.31 \\
\hline
\end{tabular}

${ }^{a}$ Enzyme activity was expressed as no product $m g$ protein ${ }^{-1} \mathrm{~min}^{-1}$

Table 1. GC-MS/SIM data for authentic BRs and CS metabolite in cultured cells of $P$. vigaris and M. pohmorpha

\begin{tabular}{lcl}
\hline Compound & $\mathrm{R}_{\mathrm{t}}$ * on GC (min) & \multicolumn{1}{c}{ Prominent ions $(m ; z$, relative intensity \%) } \\
\hline CSMetabolite** & 23.52 & $498(100), 483(9), 358(28), 328(11), 287(44), 141(93)$ \\
Authentic 26-110rCS** & 23.52 & $498(100), 483(9), 358(28), 328(11), 287(44), 141(93)$ \\
Authentic 28-110rCS** & 22.63 & $498(100), 483(8), 358(16), 328(11), 287(42), 141(52)$ \\
\hline
\end{tabular}

${ }^{*} R_{\mathrm{t}}$ : Retention time. **The sample was analyzed by GC-MS as a bismethaneboronate 


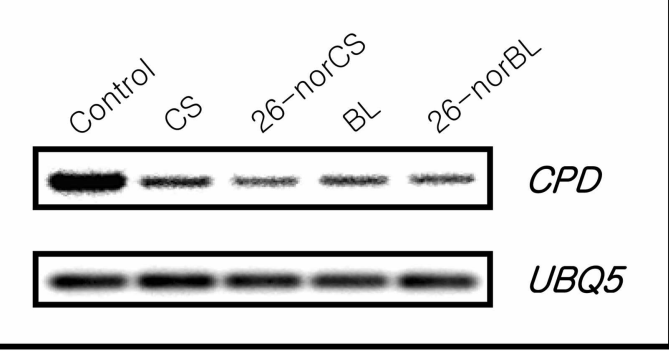

Figure 1. Feedhack inhibition of Arabidopsis $(P D D$ expression by application of IBRs. R'I-PCR was performed using R $\wedge$ A extracted from BR-treated seedlings. Products were subsequently identified by DNA gel-blot analysis. $\angle B O 5$ (ubiçuitin 5 ) expression indicates equal amourts of $\mathrm{e}$ [NA for each lane.

$\mathrm{min}^{-1}$ in the Phaseolus and Marchantia cells, respectively ( Table 2).

It has been demonstrated that $\mathrm{CS}$ is converted into a more active $\mathrm{BR}$, namely $\mathrm{BL}$, in cultured cells of $P$. whlgaris and $M$. polvmorpha. ${ }^{2,7}$ This study is the first to demonstrate that $\mathrm{CS}$ is simultaneously catabolized into a less biologically active 26 -norCS in the plant cells. To determine which reaction predominantly occurs in the plant cells, activity of CS 6oxidase, the enzyme mediating the conversions of $\mathrm{CS}$ to $\mathrm{BL}$. was subsequently examined with the same enzyme solution. After finishing the assay, [26,28- $\left.{ }^{2} \mathrm{H}_{6}\right] \mathrm{BL}$ was added for quantitative analysis, and the product was analyzed by $\mathrm{GC}$ MS. Activity for CS 6-oxidase in the Phaseolus cells was determined to be $0.09 \mathrm{ng} \mathrm{mg}$ protein ${ }^{-1} \mathrm{~min}^{-1}$, and $\operatorname{CS} 6$ oxidase activity in Marchantia cells was measured to be 0.03 ng mg protein ${ }^{-1} \mathrm{~min}^{-1}$.

It was known that $\mathrm{CS}$ and $\mathrm{BL}$ inhibit expression of Arabidopsis thaliand genes, such as DWF CPD, CY P85A and CYP85A2, which encode enzymes catalyzing earlier steps in $\mathrm{BR}$ biosynthesis. ${ }^{9.10}$ ']o ascertain whether the C-26 demethylation of $\mathrm{BR}$ diminishes feedback regulation, the effects of 26-norCS and 26-norBL on expression of $\mathrm{Arabi}$ dopsis CPD were examined. Arabidopsis CPD encodes a C$23(R)$ hydroxylase mediated conversion of cathasterone to teasterone, and 6-deoxocathasterone to 6-deoxoteasterone. As shown in Figure 1, application of 26-norCS and 26norBL, as well as $\mathrm{CS}$ and $\mathrm{BL}$, to Arabidopsis strongly inhibited the CPD gene expression, indicating that $C S / B L$ feedback regulatory inhibition is not influenced by $\mathrm{C}-26$ demethylation.

Our findings constitute the first evidence that $\mathrm{CS}$ is catabolized into 26-norCS in Phaseolus and Marchantia cells (Figure 2). Coupled with our previous finding that CS is converted into $\mathrm{BL}$ in both plants, this indicates that extra CS that is not converted into BL is catabolized into 26norCS to maintain a homeostatic level of CS in the cells. The specific activity for $\mathrm{CS}$ demethylase was measured to be ten times higher than that of CS 6-oxidase in both plants, suggesting that higher levels of $\mathrm{CS}$ than plants need is more effectively reduced by $\mathrm{C}-26$ demethylation than by conversion of CS to BL.

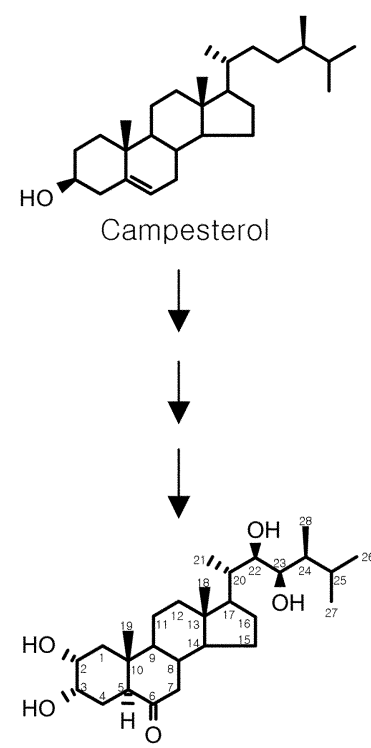

Castasterone

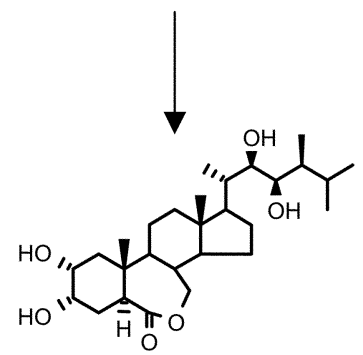

Brassinolide

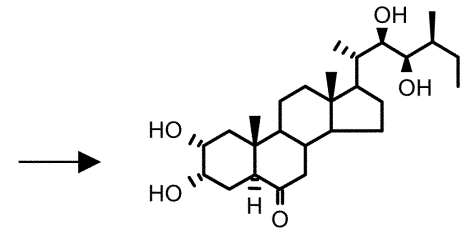

26-Norcastasterone

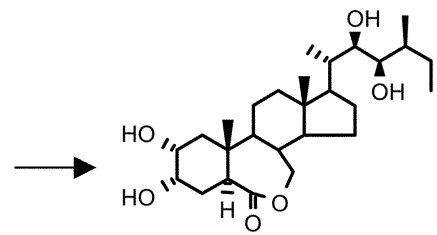

26-Norbrassinolide
Figure 2. Biosynthesis and biodegradation of $\mathrm{CS}$ and $\mathrm{BL}$ in cultured cells of P. vulgaris and M. polymorpha.

Acknowledgement. This research was supported by the Creative Initiative Research l'rogram of Chung-Ang University in 2003.

\section{References}

1. Iujuka S. In Brassinosteroids: Stenodal Ptom Hormones: Sakurai. A.. Yokotal I. Clouse. S. D. Idds: Springer-Verlage Jokşo. 1999: p 21.

2. Bajguz. A.: Tratyn. A. Phutechemistry 2003.62. 1027.

3. Sakurai. A. In Brtssinosteroids: Sterotdal Plant Hormones: Sakurai. A., Yokota. T. Clouse. S. D. Гds.: Springer-Verlag: Tokyo. 1999; p 91.

4. Bishop. (i. J.: Yokola. T. Plont ('ell Phrsiol 2001. $\$ 2.114$.

5. Noguchi. l:: rujjoka. S.: Choe. S.: Takatsuto. S.: Jax. F. E.: Yoshida. S.: Feldmann. K. A. Plam Physiol. 2000. 124. 201.

6. Mathur. I.: Molnar. G.: Fujioka. S.: Takatsuto. S.: Sakurai. A.: Yokota. T. Adam. G.: Voigt. B.: Vagy, Г.: Vaas. C.: Sehell. J.: Koncy C.: Szekeres. M. Plant J. 1998. / t. 593.

7. Kim. Y.S.: Kim. T.-W: Kim. S.-K. Bull Konern Chem. Soc. 2003. 27. 1385.

8. Yokota. T.: Arima. M.: Takahashi. .V. Tetrahedron Letters 1982. 3. 1275 .

9. Shimadat Y: Goda II:- Nakamura, A.: Takatsuto. S.: Fujiokat S.: Yoshida. S. Plant Physiol. 2003. 13/.287.

10. Mathur. I.: Molnar. (3.: lujioka. S.: Takatsuto. S.: Sakurai. A.: Yokotal 1:: Adam. G.: Voigt. B.: Nagy. F.: Maas. C.: Schell. J.: Koncz. C.: Szckeres. M. Plam J. 1998. If. 593. 